\title{
Applying a System Development Approach to Translate Educational Requirements into E-Learning
}

\author{
Said Hadjerrouit \\ Agder University College, Kristiansand, Norway
}

Said.Hadjerrouit@hia.no

\begin{abstract}
E-Learning provides a potentially powerful tool for implementing educational requirements rooted in learning theories. But still, much of the development of e-Learning is carried out without a true understanding of how learning theories can be translated into pedagogical requirements that can be implemented using learning technologies. This is because e-Learning lacks a systematic approach to the development process, resulting in poor requirements analysis and pedagogical design. This paper argues for a systematic system development approach to e-Learning to translate educational requirements into a system that supports effective learning.
\end{abstract}

Keywords: Educational requirements, e-Learning, learning cycle, learning theories, LMS, software engineering, system development.

\section{Introduction}

E-Learning is becoming a crucial resource for institutions. First, it can make education independent of time and location. Second, it opens up new possibilities for implementing pedagogical innovations where learners are expected to function as active, independent, self-reflected, and collaborative participants. Finally, it can help teachers to manage their online courses so that they can create, add, modify, customize, and reuse digital course content and learning objects. To realize the potentialities of e-Learning, there is a need for a systematic software development approach, because the lack of a systematic approach can result in poor e-Learning quality (Kay \& Knaack, 2005). In addition, the very basis of e-Learning is a pedagogical foundation based on learning theories (Conole, 2003; Govindasamy, 2002; Hamid, 2002; Harasim, 2000; Mayes \& Fowler, 2005). That is to say, progress in e-Learning will come from a better understanding of the learning process and not automatically from improved technology (Watson, 2001). Therefore, learning theories must be one of the driving forces behind e-Learning development. While a number of existing approaches to e-Learning incorporate learning theories, few of them are

Material published as part of this publication, either on-line or in print, is copyrighted by the Informing Science Institute. Permission to make digital or paper copy of part or all of these works for personal or classroom use is granted without fee provided that the copies are not made or distributed for profit or commercial advantage AND that copies 1) bear this notice in full and 2) give the full citation on the first page. It is permissible to abstract these works so long as credit is given. To copy in all other cases or to republish or to post on a server or to redistribute to lists requires specific permission and payment of a fee. Contact Publisher@InformingScience.org to request redistribution permission. grounded in software engineering principles. As a result, much of the construction of e-Learning is still carried out without a true understanding of how learning theories can be translated into pedagogical requirements.

This article is organized as follows. It starts with e-Learning research issues. The second section reports on literature review. The next section describes the 
basic dimensions of e-Learning. This is followed by the pedagogical foundation of e-Learning and information technologies used in e-Learning. Then the paper outlines a system development process model to e-Learning. A preliminary evaluation of the approach is then presented. Finally, the last sections discuss the limitations and potentialities of the approach, including some concluding remarks on further work.

\section{E-Learning Research Issues}

This work has the potential to make an important contribution to the development process of eLearning. Accordingly, the research issues of this work are threefold:

1. To propose a clear definition of the concept of e-Learning. A definition is essential because it provides the basic dimensions of e-Learning that must be taken into consideration in the development process.

2. To specify pedagogical principles rooted in learning theories. Pedagogical principles should exert stronger influences on e-Learning, because they affect its development and use.

3. To outline a systematic system development approach to e-Learning, because the cost of poor development can result in insufficient requirements analysis and inadequate pedagogical design, implementation, and evaluation.

\section{Literature Review}

This section presents an overview of approaches in the research literature associated with the research issues of this work, in particular approaches that address learning theories and the development process of e-Learning. Basically, the research literature is characterized by three elements:

- First, a number of approaches incorporate a mixture of learning theories, but few are pure derivatives of the main learning theories.

- Second, a number of approaches describe a model of developing e-Learning, but much of the construction of e-Learning is still carried out without a systematic and disciplined approach to the development process.

- Third, while a number of approaches incorporate either learning theories or a development model, or both, few made an attempt to translate learning theories into educational requirements using a systematic development approach.

\section{Learning Theories}

A number of approaches to e-Learning use a mixture of learning theories. While learning theories are the very basis of e-Learning, they are in themselves not sufficient for implementing eLearning. Learning theories must be translated into pedagogical requirements. Such a translation is a necessary step to any attempt to examine an e-Learning implementation.

The Learning Object Model (Wiley, 2000) is based upon the concept of "learning object". The use of the term object is borrowed from the object-oriented paradigm of computer science. The fundamental idea behind object-orientation relates to small-sized pieces of learning materials that can be reused many times in different contexts. However, the model is more instructional and technological rather than a model or approach to learning per se. It does not fit well the constructivist epistemology. 
Laurillard's (2002) conversational framework has been very influential in the development of eLearning among educational developers. Laurillard adopts a cognitive/constructivist approach to learning, and places emphasis on the interaction between teachers and the individual student. Laurillard considers how learning technologies can help to meet requirements for academic learning in terms of the conversational framework.

Salmon's (2002) e-Tivities approach specifies five stages of e-Learning: Access to motivation, online socialization, information exchange, knowledge construction, and development. Salmon's model relies on the constructivist learning theory. The model provides a framework for eLearning where students are engaged in online discussions. It implies a commitment to cognitive/constructivist tasks and dialogue.

The learning model presented by (Conole et al., 2004) and associated toolkits (in particular the DialogPlus Toolkit) place emphasis on social processes, facilitated by the interactions of learners and tutors. The model has been designed to help teachers to design learning activities more effectively. The model adopts a socially mediated constructivist approach.

The CSALT Networked Learning model (Goodyear, 2001) is based on both constructivist and $\mathrm{CoP}$ principles (Communities of Practice). The model uses four levels of pedagogy: Pedagogical philosophy, high-level pedagogy, pedagogical strategy, and pedagogical tactics. The model focuses on collaborative learning rooted in the constructivist learning theory.

Nash (2005) argues for the use of learning objects within the context of constructivist epistemologies, because these are considered "as pivotal to understanding how to effectively use them within online courses" (p. 217). However, it is not clear how constructivist epistemologies can be translated into pedagogical requirements that can be implemented using learning technologies.

Koohang and Harman (2005) assert that e-Learning by its very nature is rooted in the constructivist movement, where "knowledge construction takes place in individual contexts and through social disclosure, collaboration, and experience" (p. 80). In a constructivist environment, learning is authentic and multiples perspectives that stimulate "cooperative and collaborative learning are encouraged" (p. 81).

\section{Development Approaches}

Much of the construction of e-Learning is still carried out without a systematic approach to the development process, resulting in poor analysis, design, and evaluation. (Kay \& Knaack, 2005) conducted a review of 58 articles. The review revealed "only five papers that documented the process of developing a learning object" (p. 231). Moreover, "only three studies did a formal descriptive evaluation of the final product" (p. 232). This is in line with the following literature review.

Krauss and Ally (2005) take a pragmatic approach to the development of learning objects and a combination of learning theories, including elements of behaviorism, cognitive theory, and constructivism. The role of the instructional designer is to prescribe an appropriate strategy and context for learning based on learning theories. However, the method presented in this paper cannot be considered as a system development approach on the basis of software engineering principles.

Cohrane (2005) uses participatory action research as a methodology for developing learning objects, involving successive cycles of reflection and feedback between researching and developing learning objects. This approach is important for collecting and analyzing data using qualitative methods. Action research is of paramount importance for educational research, but it not a system development approach relying on software engineering criteria. 
Similarly, MacDonald et al. (2005) adopt a collaborative approach to the development of learning objects, involving collaboration among subject specialists, technology experts, and researchers for assessment. The approach is associated with three phases: (1) creating a paper-based document for face-to-face class; (2) re-purposing this document into an electronic resource for online course; and (3) creating a rich, interactive online learning object. While the collaborative dimension is crucial for any e-Learning development, this method can hardly be considered as a system development methodology.

Varlamis and Apostolakis (2006) advocate a life cycle of e-Learning process. The life cycle comprises of four phases: design, production, deployment, and assessment. The goal of this model is to minimize development and deployment costs, facilitate re-usability of content and increases. While the life cycle is a worthwhile contribution to the development of e-Learning, the translation of learning theories into pedagogical requirements is not sufficiently emphasized.

Salas and Ellis (2006) present a development approach to learning objects in a higher education setting. The approach describes five steps: (1) develop clear learning objectives for each course; (2) model all existing content; (3) split all existing content into discrete objects; (4) identify common elements of content across courses; (5) develop a learning object for each discrete content element. While this approach is important to the development of courses, it is more instructional and technological rather than a system development approach.

\section{Basic Dimensions of E-Learning}

There is no clear and unequivocal definition of the concept of e-Learning. Definitions in the research literature are partially exclusive and sometimes contradictory, and there are few common terms used consistently (Anohina, 2005; Cohen \& Nycz, 2006; Nocols, 2003). It is difficult to distinguish the term "e-Learning" from terms such as "virtual learning", "network learning", "online learning", "multimedia-based learning", "Web-based learning", "Internet-enabled learning", and similar terms. E-Learning is often seen as learning where the Internet and the Web play an important role. The term is also employed in a broader sense, as learning where any electronic technology is used, but it excludes aspects that might fit under "distance learning", but are not electronic, such as books.

An attempt to define e-Learning, from a technological point of view, is to look at the relationships between e-Learning and some closely related concepts: Internet-based learning, Web-based learning, online learning, and computer-based learning:

- The concept of internet-based learning is broader than Web-based learning. Hence, the Web is only one of the Internet services that use HTML, browsers, and URL. Internet offers many other services, not only Web, but also e-mail, file transfer facilities, etc. Learning could be based on the Web, but also as correspondence via e-mail.

- Online learning could be organized through any network. Thus, Internet-based learning is only a subset of online learning.

- Learning may take place via any electronic medium. It is not automatically connected to a network. Learning includes computer-based learning that is not network-based.

As a result, e-Learning includes both network-based (online learning, Internet-based learning, and Web-based learning) and non-network-based learning or computer-based learning (Figure 1). 


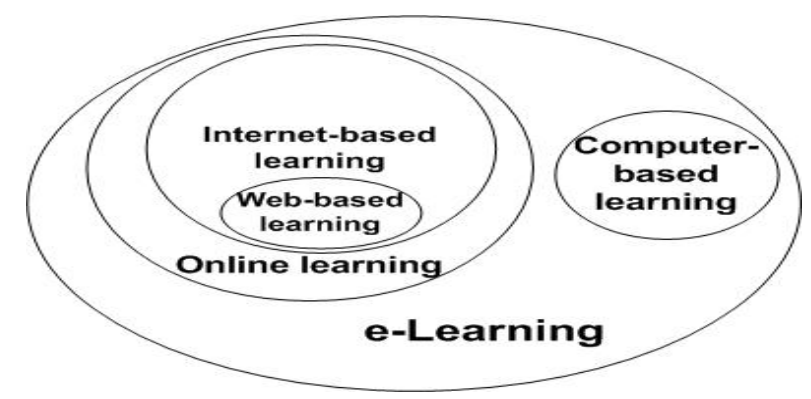

Figure 1: Technological dimensions of e-Learning

Furthermore, the concept of e-Learning is employed in a broader sense, as learning that takes place via a combination of face-to-face and e-Learning. A mixture of face-to-face and e-Learning is known as hybrid or blended e-Learning (Bonk \& Graham, 2006; Buzzetto-More \& Pinhey, 2006).

Finally, in addition to the electronic delivery technology, including all form of information and communication technologies, e-Learning incorporates two important dimensions:

- Learning theories, instructional strategies, and pedagogical approaches.

- The subject matter and associated content to be learned.

\section{Pedagogical Foundation}

Important to the design of e-Learning is a pedagogical foundation built on solid learning theory. Literature reviews suggest that learning theories can be related to three main models:

- Behaviorist learning,

- Constructivist learning

- Collaborative learning

The remainder of this section describes the most important characteristics of the learning theories and presents a three-stage model - the learning cycle - that retains the features of each one.

\section{Learning Theories}

In terms of instruction, the behaviorist learning theory assumes that the goal of learning is to efficiently transmit knowledge from the instructor to the learners (Lin \& Hsieh, 2001; Steffe \& Gale, 1995). In a behaviorist setting, instructors are clearly central to learning activities. However, while behaviorism promotes stability and certainty with respect to knowledge acquisition and learning outcomes, there are few opportunities for learners to express their own ideas, because behaviorism does not engage the mind appropriately. The behaviorist model is therefore criticized for stimulating surface learning and knowledge reproduction. However, behaviorist learning is suitable for novice learners, as they need transferable knowledge from the instructor.

In contrast to behaviorism, the constructivist learning theory views knowledge as a constructed entity made by each and every learner through a learning process. Constructivism frames learning less as the product of passive transmission than a process of active construction whereby the learners construct their own knowledge based upon prior knowledge (Lin \& Hsieh, 2001; Duffy, Lowyck \& Jonassen, 1993; Piaget, 1971; Steffe \& Gale, 1995). Constructivist learning requires learners to demonstrate their skills by constructing their own knowledge when solving practical problems. The constructivist model calls for learner-centered instruction because learners are as- 
sumed to learn better when they are forced to discover things themselves rather than when they are instructed. In a constructivist setting, teachers serve primarily as guides and facilitators of learning, not as transmitters of knowledge.

Whereas in the constructivist paradigm learning is assumed to occur as a learner interacts with study material, learning emerges, according to the collaborative learning theory, through interaction of learners with other people, e.g. instructors and fellow learners (Lin \& Hseih, 2001; Lowyck \& Poeysae, 2001; Vygotsky, 1978). Learning occurs as learners exercise, test, and improve their knowledge through discussion, dialogue, collaboration, and information sharing. Vygotsky argued that the way learners construct knowledge, think, reason, and reflect on is uniquely shaped by their relationships with others. He argued that the guidance given by more capable others, allows the learner to engage in levels of activity that could not be managed alone. This guidance occurs in the Zone of Proximal Development (ZPD), which is the difference between what a learner can do independently and what can be accomplished cognitively with scaffolding from more knowledgeable others.

\section{The Learning Cycle}

The literature on learning theories points to the fundamental philosophical differences between them (Lin \& Hsieh, 2001). However, in practice, a mix of learning theories is being used. Indeed, instructional designers tend to believe that what works in a learning situation is a subtle combination of learning theories. Thus, instructional designers must allow circumstances surrounding the learning situation to help them decide which approach to learning is most appropriate. According to (Karagiorgi \& Symeou, 2005), it is necessary to realize that some learning problems require prescriptive solutions, whereas other are more suited to constructivist and collaborative learning.

Along the same line of argument, Mayes and Fowler (Mayes \& Fowler, 1999) proposed a threestage model or learning cycle, in which they identified three types of learning - conceptualization, construction, and dialogue. The essential characteristic of the learning cycle is that it describes a continuous cycle of gradual refinement of understanding. Accordingly, learning develops in three phases, beginning with conceptualization, progressing through construction to dialogue:

1. The conceptualization phase is characterized by the process of interaction between the learners' pre-existing framework and new knowledge.

2. The construction phase - the intermediate phase of learning - refers to the process of building and combining concepts through their use in the performance of meaningful tasks.

3. The dialogue phase refers to the testing of conceptualizations and the creation of new concepts during conversation with both fellow learners and instructors. Dialogue emerges through collaborative learning.

At any stage of e-Learning implementation there needs to be an emphasis on the three stages of the learning cycle: learning as behavior, learning as knowledge construction, and learning as dialogue and social practice. In this perspective it is important to consider the nature of the learning outcomes that are sought through the implementation of the learning cycle. Bloom's taxonomy of Educational Objectives (Bloom, 1956) is used as a general system for classifying learning outcomes to be achieved: knowledge, comprehension, application, analysis, synthesis, and evaluation. The conceptualization phase focuses on the acquisition of knowledge. The construction phase emphasizes comprehension, application, and analysis. The dialogue phase encourages synthesis and evaluation. 


\section{Information Technologies Used in E-Learning}

From a pedagogical point of view, learning theories can be implemented to achieve three categories of e-Learning using information technologies:

1. The behaviorist learning theory can be applied to e-Learning to support the transmission of knowledge from the instructor to the learners.

2. The constructivist learning theory can be applied to e-Learning to support task-based activities rather than the transmission of knowledge from the instructor to the learners.

3. The collaborative perspective of learning can be applied to e-Learning to support collaborative learning, dialogue, and discussion with both the instructor and fellow learners.

In line with these considerations, Mayes and Fowler (1999) characterized the types of information technologies used to achieve each stage of the learning cycle as primary, secondary, and tertiary courseware:

1. Primary courseware is intended mainly to present the subject matter.

2. Secondary courseware focuses on the set of software tools that support the performance of task-based activities.

3. Tertiary courseware is the learning material that has been produced by previous learners. It may consist of dialogues, discussions, and conversations between learners and teachers.

Mayes and Fowler's model has been adapted by Roberts (2003) to categorize three uses of the Web. Similarly, this model can be adapted to categorize three uses of e-Learning (Figure 2).

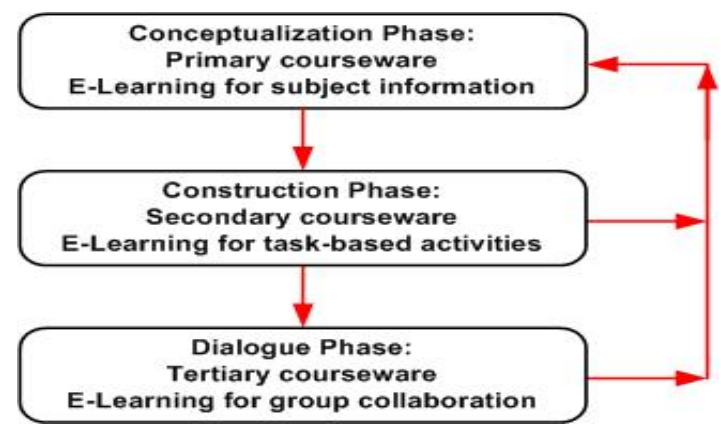

Figure 2: Mayes and Fowlers' learning cycle as feedback loop adapted to e-Learning

\section{System Development Issues of E-Learning}

Before presenting the development process model to e-Learning in the next section, it is important to understand the underlying educational, pedagogical, and software engineering issues of the model. These are as follows:

- The evolutionary perspective of e-Learning.

- The development process model that deals with the evolutionary perspective of eLearning.

- The object-orientation of the modeling process.

- The modeling language UML that supports the building of object-oriented visual models. 


\section{An Evolutionary Perspective}

E-Learning needs to evolve rapidly in order to ensure the relevance, correctness, and completeness of the information available online. Thus, a continuous evolution is of crucial importance for the quality of e-Learning. The major elements that influence a continuous evolution of any eLearning system are:

- E-Learning calls for continuing update, change, and refinement of course content. Thus, e-Learning content has to be constantly evaluated against what is in fact delivered online.

- E-Learning has to take into consideration the evolution of curriculum due to institutional changes, such as legal and ethical environment, organization and timetabling of courses, changes related to teachers, course developers, technical staff, and students.

- Another element of the evolutionary context is partly a direct result of the multi-user feature of e-Learning. The large number of learners, with their heterogeneous needs and learning styles, makes a continuous evolution of e-Learning necessary.

- Furthermore, the evolutionary context of e-Learning partially results from continuing advances in the information technology infrastructure, e.g. programming languages, Web technologies, mobile, pervasive and smart devices. A broad range of existing e-Learning technologies are not fully developed, and call therefore for continuing improvement.

- Finally, e-Learning is affected by the evolution of learning theories and learning environments. These exert strong influences on educational practice and development of eLearning, because they offer a springboard for pedagogical innovations.

\section{Evolutionary Process Model}

An ideal process model for the development of e-Learning would help teachers, educational designers, and developers address the complexity of e-Learning, deal with the evolution and change, and deliver the system as quickly as possible.

However, considering that developing e-Learning is not simply another form of traditional software development, even if both involve analysis, design, and implementation, there is not necessarily any existing system development process model that makes sense for e-Learning.

Conventional system development approaches (Pressman, 2000) and development process models that are devoted to Web-based development such as e-commerce (Balasubramaniam, PriesHeje, \& Baskerville, 2003; Conallen, 1999; Murugesan \& Ginige, 2001), and extensions of these approaches to Web teaching (Horton, 2000) are too general. They are not adequate to be applied to e-Learning, mostly because they do not deal with teaching and learning issues that are specific to e-Learning. Furthermore, domain-specific methodologies, which are exclusively devoted to Web-based learning (Frantiska, 2003; McCormak \& Jones, 1998; Montilva, Sandia \& Barrios, 2002; Powell, 1998), do not explicitly deal with requirements that are proper to e-Learning, because they fail to address contextual and evolutionary issues of e-Learning (Govindasamy, 2002; Hamid, 2002; Harasim, 2000). In addition, few approaches concentrate on the entire development process from analysis to evolution.

Moreover, the linear sequential model known as the waterfall model is not flexible enough to be applied to e-Learning, because it does not deal with evolution, change, and feedback to previous steps. But, the waterfall model is interesting from the management point of view, since it can help developers plan everything from the very beginning (Powell, 1998; Pressman, 2000). The spiral model, which also addresses the entire development process, is relatively complicated and diffi- 
cult to manage in order to be applied to e-Learning, but it can help developers, in particular during the analysis phase, to minimize risks by focusing on what really matters.

As a result, previously developed system development process models do not fit the specifics of e-Learning. Hence, it may be necessary to combine the advantages of pre-existing models, and eventually modify them, to meet the specific requirements of e-Learning.

Given the evolutionary character of e-Learning, it seems that the most suitable process model for e-Learning is the evolutionary process model, which modifies an early prototype until it provides all required features. The model is suitable for e-Learning, because the process often involves feedback to earlier phases. This model is however not without problems since e-Learning systems are evolving constantly. It is thus difficult to determine when they are going to end. Finally, the model must rely on reusability since the reuse of learning objects and components is a necessary option for e-Learning.

As a result, it seems that the most suitable process model for e-Learning is a modified evolutionary process model that includes some important aspects of other process models. Thus, the key issues of developing e-Learning are:

- First, e-Learning needs a structured evolutionary process model with feedback to previous phases in order to deal with change and evolution.

- Second, e-Learning needs to reuse learning objects, so that developers are not forced to start over again when they design e-Learning for new courses.

- Third, particular attention must be placed on the analysis of the teaching and learning environment, that is to say the scope of the system, at an early stage, since it is of crucial importance to understand environmental factors that affect e-Learning.

- Finally, the model must include an evaluation phase to ensure that pedagogical principles and learning issues are kept in mind.

\section{Object-Oriented Modeling}

The very nature of e-Learning makes the use of object-oriented modeling an essential prerequisite for an evolutionary development process. An object-oriented model is elaborated through analysis, design, coding, and evolution phases - details are added in successive iterations; changes and refinements are introduced as needed. Development by elaboration is possible because all objectoriented models are semantically rich and based on the same "language" - the underlying vocabulary is essentially the same (Maciaszek, 2001).

Object characteristics make the use of object-oriented modeling very relevant for the evolutionary character of e-Learning information, which has to be constantly updated, changed, elaborated, refined, and evaluated against what is in fact delivered online. The principles of object-oriented modeling allow the efficient manipulation of e-Learning information.

Moreover, the use of objects is very well suited to designing e-Learning, because objects provide multiple perspectives and modes of representation. In addition, Youm \& Black (2005) consider that object-oriented design "could have implications for the future of learning materials and instructional technologies as well as for the immediate use of existing educational resources" (p. 1585). 


\section{Modeling Notation}

To describe object-oriented models there is a need for a modeling language to build visual models (Maciaszek, 2001; Stevens \& Pooley, 2000). The Unified Modeling Language (UML) allows developers to express analysis and design models using a modeling notation. UML has a strong visual component and supports reusability. It is expressive enough and easy enough to understand by all people involved in the development process. UML uses five different views that describe the system from distinctly different perspectives. Each view is defined by a set of diagrams. The following views are the most important for modeling e-Learning:

- User model view. This view represents the system from the user's perspective (called "actors" in UML). The use case is the modeling approach of choice for the user model view.

- Structural model view. This view describes the internal structure (classes, objects, and relationships) of the e-Learning system. There are a number of relations that can be modeled using the structural model view: $1 . .1$ (one-to-one), $1 . . *$ (one-to-many), 1-0..* (oneto-none or one-to-many), $1-1 . . *$ (one-to-one or one-to-many). The "*" represents the range: 0. .many.

\section{E-Learning Development Process Model}

The section outlines an evolutionary development process model to e-Learning and associated software life cycle. The model is grounded in the pedagogical, educational, and engineering considerations described in the previous section. The model encompasses two types of processes:

1. The project management process is concerned with the activities that are required to manage the development process.

2. The development process is related to the activities that are required to produce eLearning

As illustrated in Figure 3 an evolutionary development life cycle is an orderly set of activities conducted and managed for each e-Learning project. The life cycle identifies the phases along with e-Learning moves from the system scope to evolution. The life cycle includes nine phases.

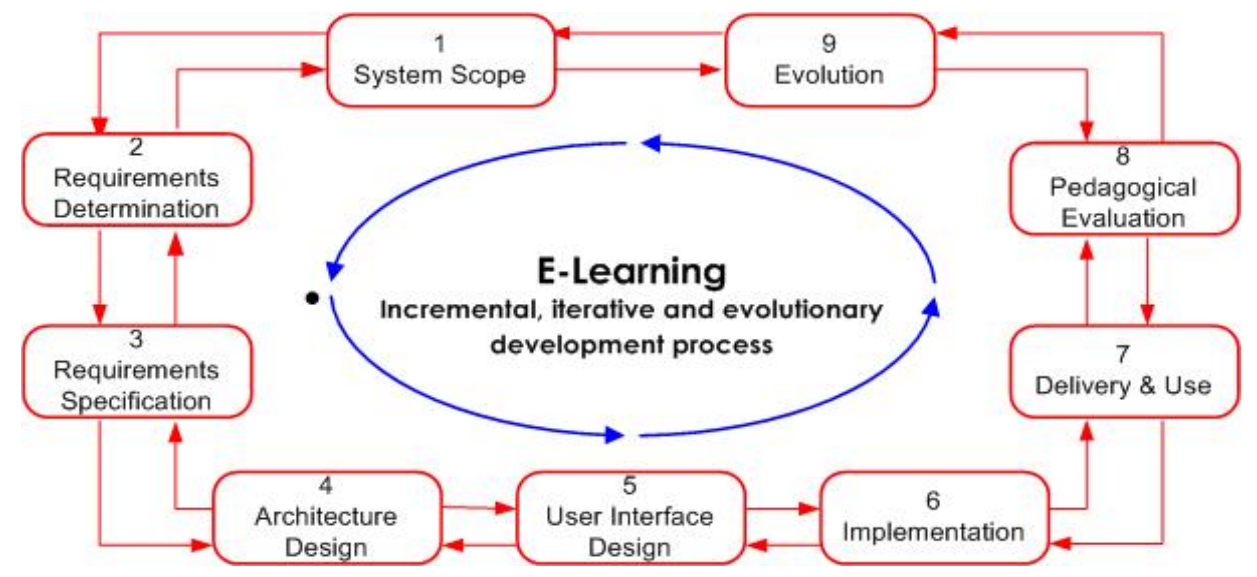

Figure 3: Evolutionary development process model to e-Learning

\section{Phase 1: System Scope}

A crucial concern in e-Learning development is the scope of the system being developed due to ever changing requirements. The system scope ensures that the requested changes do not go be- 
yond the accepted scope. Basically, the system scope can be determined through the identification of the contextual elements that directly influence e-Learning. Any e-Learning system is a part of a larger environment, which influence each other by exchanging information (Ahlemann, Haas, \& Hoppe, 2003; Pahl, 2003). The environment can be characterized as the scope of the system, which can be described with five dimensions: teachers, learners, learning theories, information technology, and the institution, in which e-Learning operates (Figure 4). UML does not provide a good visual model to define the scope of the system. The old-fashioned context diagram of DFDs (Data Flow Diagrams) is more appropriate to describe this task. The rectangles around e-Learning designate elements that directly affect the system. The arrows depict data flows. Basically, there are five elements that directly influence e-Learning:

1. E-Learning obtains information from teachers. This information includes the content of the course, course topics and schedule, course assessment, and related study material. This information is delivered by teachers and constitutes the basis for course requirements. Content is a key element since it is one of the differentiating factors that separates effective from ineffective e-Learning (Govindasamy, 2002). Content should not be treated as a self-sufficient substance that is independent of the environment where it is learned and used.

2. E-Learning obtains information from learners and their characteristics. Learners have different knowledge background and learning styles. They differ in how they view the learning environment. Basically, learners within different social-cultural environments react differently to competition, authority figures, and gender differences, etc. Hence, values and learning styles implicitly affect the way in which learning is undertaken (Strodher, 2003). For instance, learners may have difficulties overcoming their traditional roles as passive listeners, and they may have difficulties to adapt to the concept of eLearning.

3. E-Learning is affected by learning theories and associated pedagogical strategies. These form the very basis of any e-Learning system. Learning theories are one of the major forces behind e-Learning, because they strongly affect its implementation. Hence, important to the design of e-Learning is a pedagogical foundation built on solid learning theory. Learning theories can be related to three main models: behaviorist, constructivist, and collaborative learning. e-Learning obtains this information from educational researchers and practitioners.

4. E-Learning is affected by the information technology being used, which refers to the hardware and software infrastructure of e-Learning. In contrast to traditional software systems, which are built using an homogeneous technology infrastructure, e-Learning systems run in a heterogeneous computing environment that includes multi-platforms, multi-browsers, multi-software, and multimedia support. This environment has programming languages, automated tools, and many other means of implementation, such as LMSs (Learning Management Systems). In addition, wireless technologies are triggering a new wave of mobile e-Learning.

5. Finally, e-Learning is influenced by the institution or organization, in which the system operates. The institutional context includes curricular issues, such as timetabling and syllabus of courses. In addition, legal and ethical issues play an important role since eLearning is affected by legal constraints, ethical conventions, including copyright protection of knowledge producers, security against knowledge manipulation and all forms of cheating (Graf, 2002). Finally, educational policies of the institution exert strong influences on e-Learning. 




Figure 4: System scope of e-Learning

\section{Phase 2: Requirements Determination}

The requirements determination phase captures requirements and defines them as natural language statements (Maciaszek, 2001). E-Learning developers through consultation discover the system requirements. The consultation involves learners, teachers, educationalists, information technology staff, and institutional leaders (Figure 5). This phase involves various techniques of gathering information, such as structured and unstructured interviews, questionnaires, study of documents, etc. The result of this phase is a requirement document. This is mostly a narrative text document with some informal diagrams and tables. There are five types of requirements for eLearning:

1. Teachers' requirements elicited from teachers constitute the course knowledge. These capture the educational goals, the teaching content and associated topics, teaching methods, the type of concepts and skills that learners need to acquire, assessment procedures, etc.

2. Pedagogical requirements derived from educationalists (educational researchers and practitioners) specify the most appropriate learning strategies rooted in current learning theories, e.g. behaviorism, constructivism, collaborativism, and the three-stage model of learning and associated learning cycle.

3. Learners' requirements elicited from learners describe the learners' characteristics, such as learner's learning styles and skill levels, and learner's prior knowledge and experience. The specification of learners' characteristics allows the consideration of individualized learning.

4. Technological requirements from information technology staff refer to the hardware and software platform of e-Learning (Web, Internet, LMS, LCMS, etc.) and associated set of technical design criteria, such as flexibility, interactivity, reliability, efficiency, site structure, cross platform, screen appearance, navigation, linking, multimedia design.

5. Institutional requirements elicited from institutional leaders refer to the organization, in which the system operates. These requirements describe legal constraints, ethical conventions, copyright protection of knowledge producers, security against knowledge manipulation and all forms of cheating, as well as educational policies and privacy considerations 


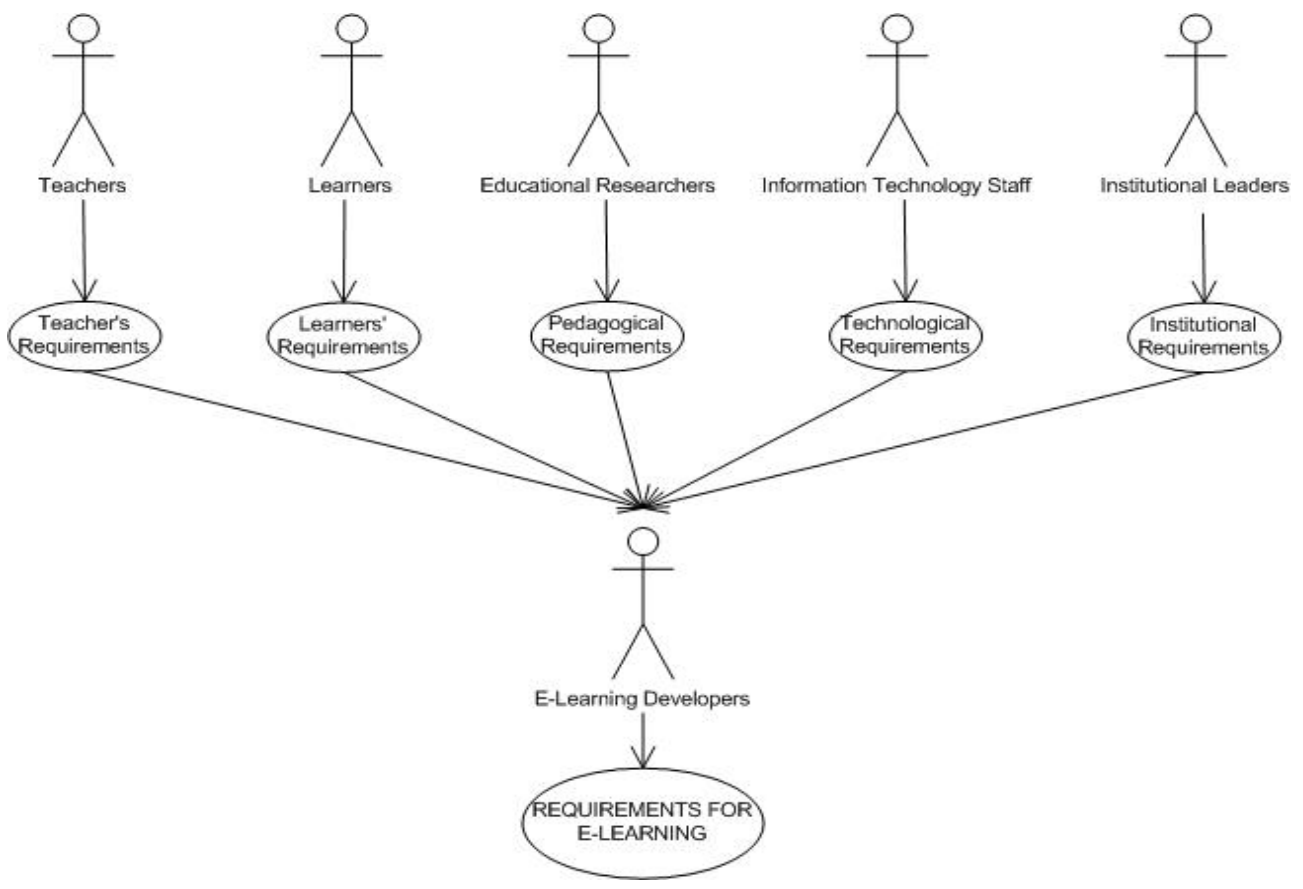

Figure 5: Requirements determination

The requirements need a set of features for their definition, while their suitable combination produces an e-Learning system.

\section{Phase 3: Requirements Specification}

The requirements specification phase is concerned with a rigorous modeling of the requirements defined during the requirements determination phase. This phase begins when the developers start modeling the requirements using UML. The two most important specification techniques with UML are class modeling and use case modeling.

The modeling process focuses on three types of requirements: Learners' requirements, teachers' requirements, and pedagogical requirements. This results in three modeling perspectives:

- User modeling specifies the users of e-Learning. Users can be modeled with class diagrams at a high level of abstraction.

- Functional modeling specifies e-Learning from the functional perspective. Functions can be modeled with use case diagrams at a high level of abstraction.

- Pedagogical modeling specifies e-Learning from the pedagogical perspective. It can be modeled with class diagrams at a high level of abstraction.

\section{User modeling}

User requirements are specified through the classes that represent the users of e-Learning: Learners, teachers, and administrators:

- Learners use e-Learning in order to participate in the educational process. In fact, learners are the most important users, in the sense that e-Learning is being used in order to satisfy their educational needs. 
- Teachers (instructors, tutors, etc.) use e-Learning in order to provide new study material, update the existing one, supervise, coach, assist, and evaluate the students' learning, participate in discussions, communicate and exchange personal messages, collect, assess, and return deliverables, comment project work, review learning activities, etc.

- Administrators undertake the support of all the users of e-Learning. They administrate security and access rights to the system, network operations, monitor and repair database connections and operations, as well as server problems, maintain the system, produce statistics, etc.

The class diagram in Figure 6 contains a generic class User and three associated classes: Learner, Teacher, and Administrator. Users (class User) have rights (class Rights), which allow them to login with a username and a password. Thus, class Rights must be linked to User. In addition, a class Login is needed in order for the users to login. The class diagram shows the most apparent relations between the classes. The classes are described with primitive attributes.



Figure 6: User requirements: High level class diagram

\section{Functional modeling}

Functional modeling includes the definition and specification of the set of operations (or use cases) that e-Learning must provide to users: teachers, learners, and administrators. A subset of operations is shown in Figure 7. These can be divided into teaching, learning, and administrative operations:

- Teaching operations and associated use cases are: register teacher information, teacher login, update course content (display, create, change, and delete course content), review task-based activities, answer questions, assess student learning, check course evaluations, etc.

- Learning operations and associated use cases are: register learner information, learner login, display course content, perform task-based activities, perform dialog and group collaboration, perform project work, perform assessment, perform courseware evaluation, etc.

- Administrative operations and associated use cases are: update user information, produce statistics, and create security and access rights. 


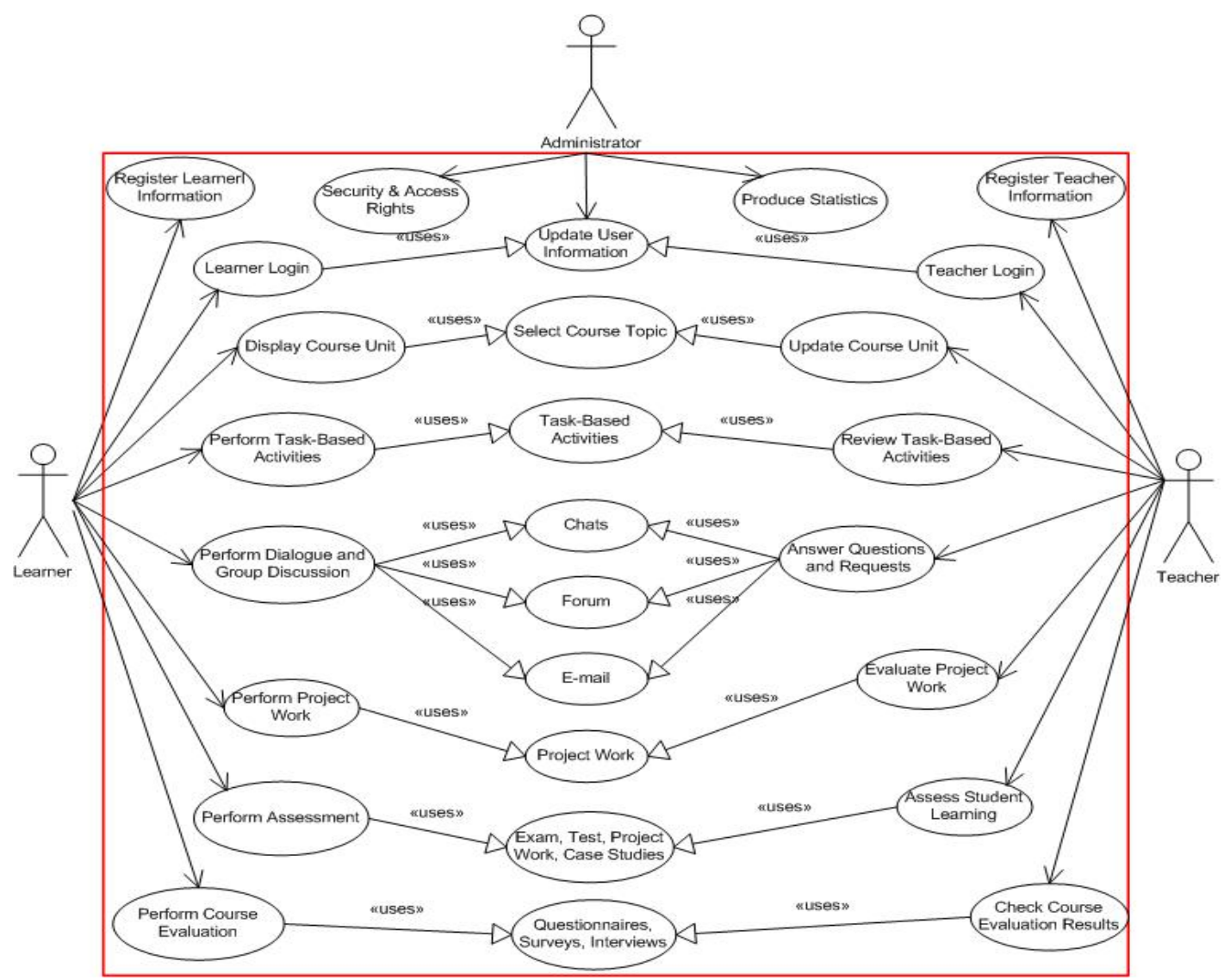

Figure 7: Functional requirements: High level use case diagram.

A typical learner's scenario consists of the following steps. A learner must register personal information that must be validated by the system. This information is stored in the learner's profile. The use of e-Learning begins when the learner decides to login with a username and a password. There are a number of scenarios for using e-Learning. Learners can select course material, and then display course topics and related study material. Learners can perform task-based activities, ask questions about them, and discuss their solutions with the teacher. Learners start with taskbased activities, read course topics, and than discuss different issues with the teacher, etc.

Teacher's scenarios consist of delivering and updating course content, modifying and reviewing task-based activities, assessing student learning, answering questions and requests related to taskbased activities and course topics, checking course evaluations, etc.

\section{Pedagogical modeling}

Pedagogical modeling is organized around the modeling of the learning cycle and associated three phases of learning: conceptualization, construction, and dialogue phases. Hence, pedagogical modeling includes the definition and specification of three data models:

1. A behavioral data model for the conceptualization phase of the learning cycle

2. A constructivist data model for the construction phase of the learning cycle

3. A collaborative data model for the dialogue phase of the learning cycle

For modeling behaviorist learning, e-Learning should be designed to support the presentation of the subject matter. Hence, the requirements elicited from the conceptualization phase constitute 
the very basis for the behavioral data model. The model contains six main classes and thirteen associated classes (Figure 8). The classes are described with primitive attributes. The main classes are: Courseware Evaluation, Course Information, Course Unit, Prerequisite, Learning Assessment, and Assignment. The terminology described in section "Modeling Notation" is used to specify the relations between the classes. The class diagram shows the most relevant attributes:

a) Courseware Evaluation consists of one Standard Questionnaire.

b) Course Information has one Schedule and is related to none or many Past Version of the Course.

c) Course Unit consists of one or many Topic and Study Material, respectively. A Topic may have many Subtopic.

d) Learning Assessment relies on one or many Exam and one or many Compulsory Assignment, respectively. Exam may consist of one or many Regular Exam and none or many Supplementary Exam.

e) Assignment may consist of one or many Compulsory and Non-Compulsory Assignment, respectively. Both Compulsory and Non-Compulsory Assignment are associated with one or many Submission. Each Submission may be related to one or many Feedback.

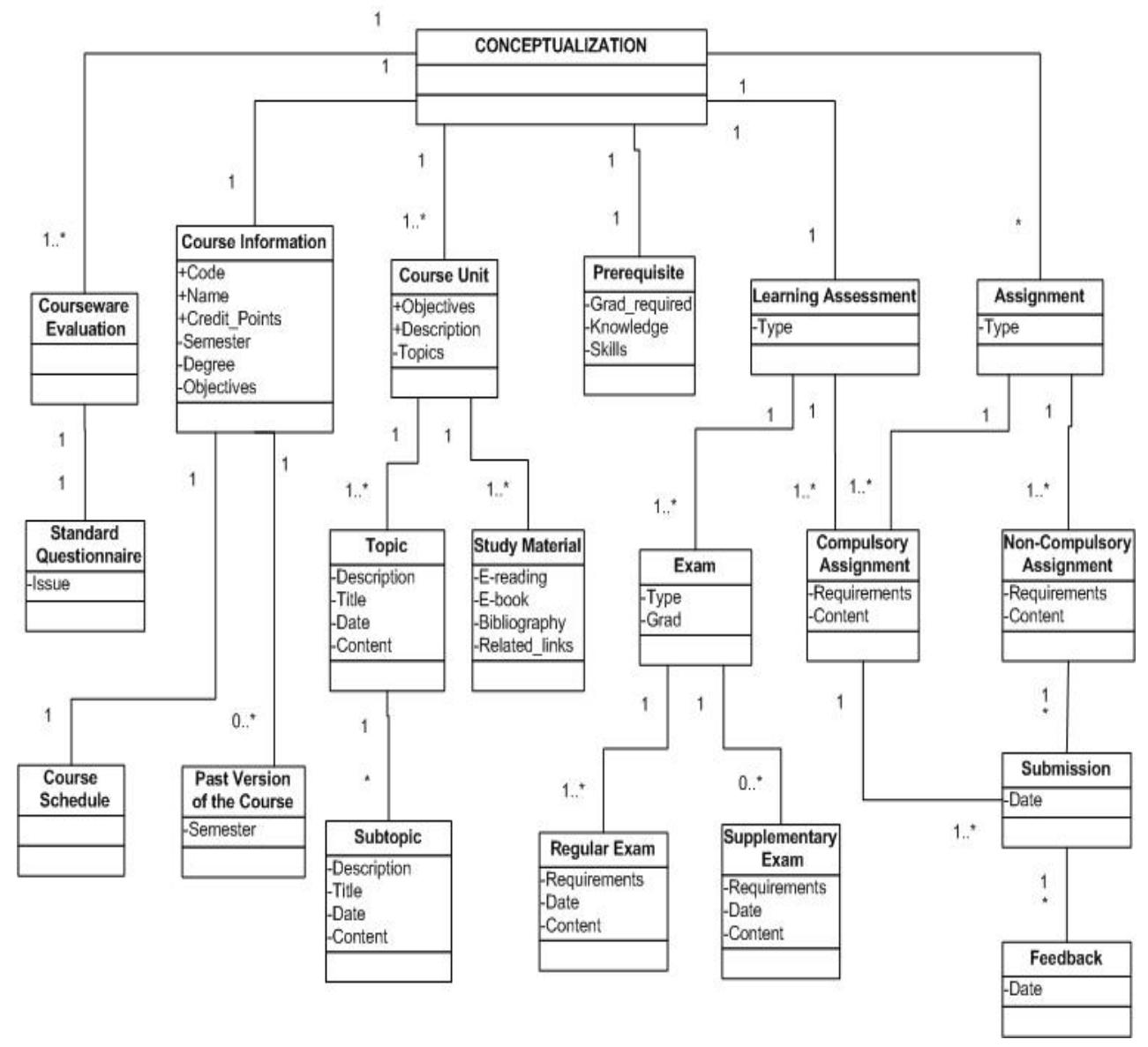

Figure 8: Conceptualization phase: High level class diagram

For modeling constructivist learning, e-Learning must be designed to support task-based activities rather than the presentation of the subject matter. Hence, the requirements elicited from the construction phase constitute the very basis for the constructivist data model. The model contains 
four main classes and seventeen associated classes (Figure 9). The classes are described with primitive attributes. The main classes are: Task-Based Activity, Learning Assessment, Prerequisite, and Courseware Evaluation. The terminology described in section "Modeling Notation" is used to specify the relations between the classes. The class diagram shows the most relevant attributes:

a) Task-Based Activity consists of many Case Study, Interactive Software, and Project Work, respectively. Interactive Software has appropriate links to none or many Database, Searching, Multimedia, VRML/Animation, and Simulation, respectively. Project Work may consist of none or many Past Project and one or many New Project, respectively.

b) Learning Assessment relies on many Project Assessment and many Case Study Assessment. Project Assessment may be related both to Past Project and New Project, which themselves may have many Submission. Each Submission may be associated with many Feedback. This is also the case for Case Study Assessment.

c) Courseware Evaluation is performed using one or many Interview and one or many Survey Questionnaire, respectively.

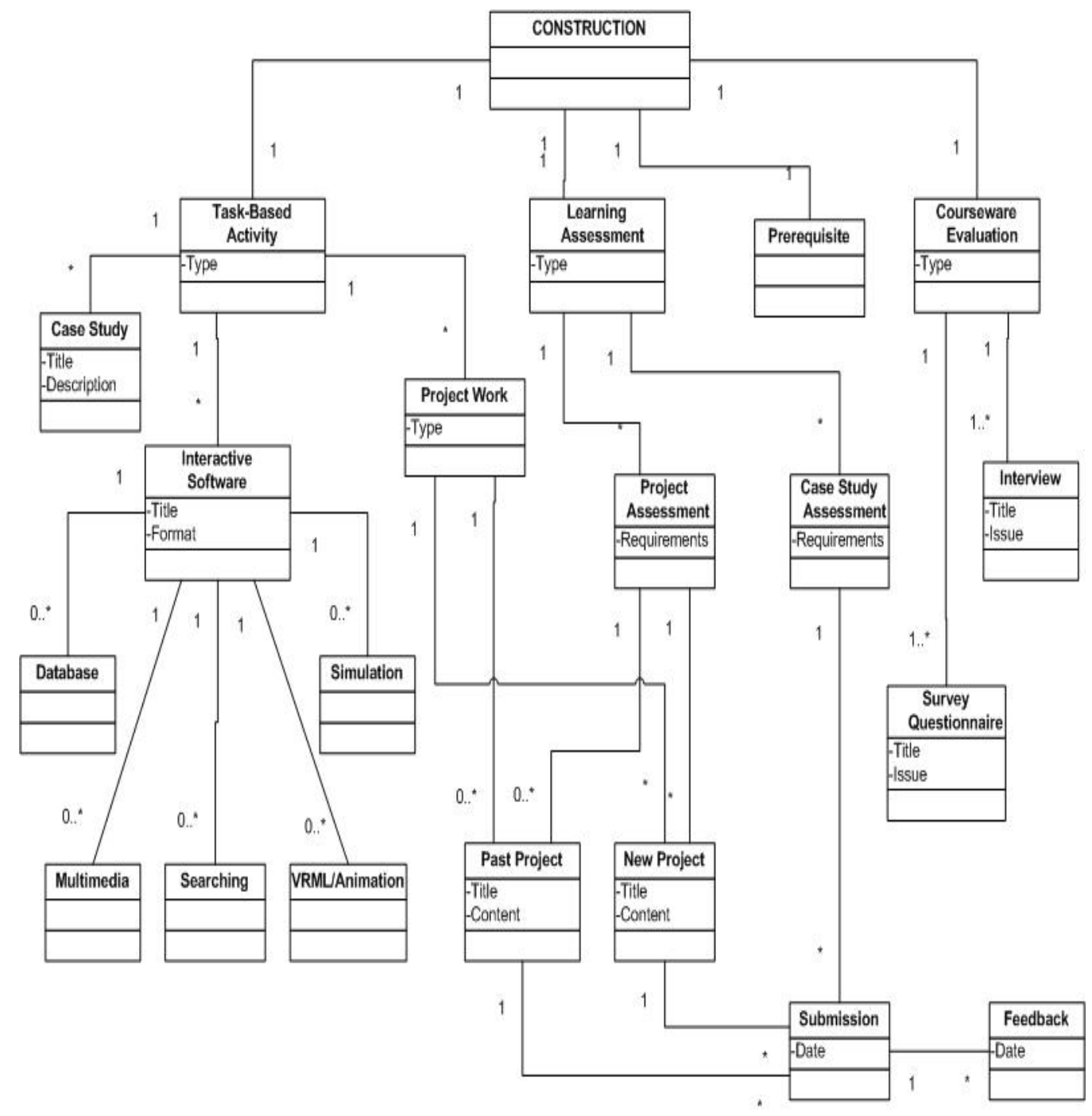

Figure 9: Construction phase: High level class diagram 
For modeling dialogue activities, e-Learning should be designed to support collaborative learning, enabling students to ask questions and receive feedback, collaborate with fellow students, discuss solutions to project work, etc. Hence, the requirements elicited from the dialogue phase constitute the very basis for the collaborative data model. The model contains five main classes and sixteen associated classes (Figure 10). The classes are described with primitive attributes, such as Type, Date, Topic, etc. The main classes are: Courseware Evaluation, Project Work, Learning Assessment, Collaborative Activity, and Prerequisite. The terminology described in section "Modeling Notation" is used to specify the relations between the classes. The class diagram shows the most relevant attributes:

a) Courseware Evaluation relies on one or many Interview and one or many Survey Questionnaire.

b) Project Work is associated with many Participation in Project Work, which may be related to many Submission. Each Submission is associated with many Feedback.

c) Learning Assessment relies on many Participation in Project Work and many Participation in Collaborative Activity.

d) Collaborative Activity is performed using many Online Discussion and Online Workspace, respectively. Online Discussion may be Synchronous or Asynchronous. Synchronous is related to many Chat. Asynchronous consists of many Forum, E-mail, and Mes-

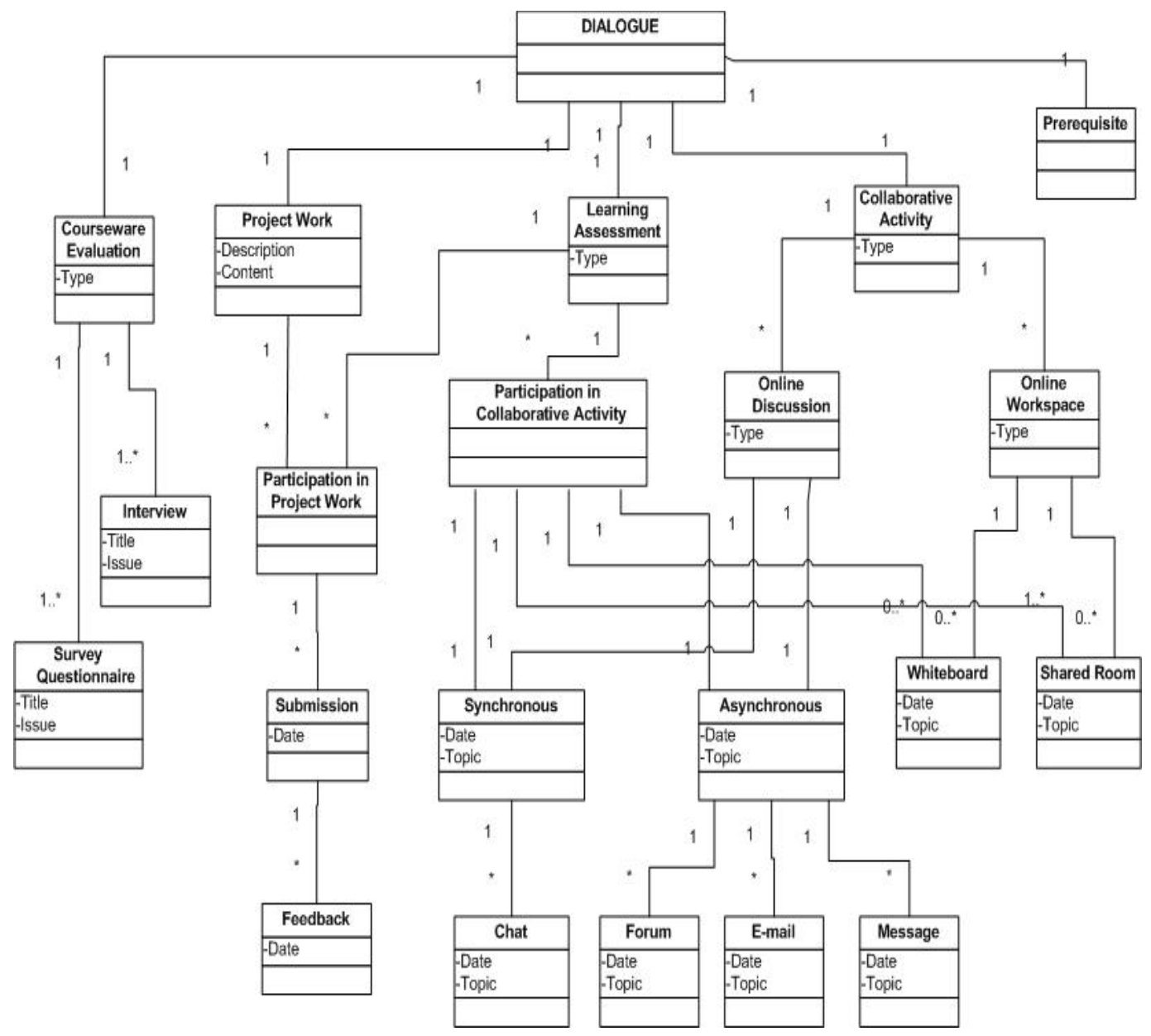

Figure 10: Dialogue Phase: High level class diagram 
sage. Online Workspace may be none or many Whiteboard and none or many Shared room, respectively. Finally, Participation in Collaborative Activity is related to Chat, Forum, E-mail, Message, Whiteboard and Shared Room.

\section{System Constraints}

System constraints describe how e-Learning is constrained when accomplishing its functions (Maciaszek, 2001). Accordingly, constraints are set with regards to the following requirements:

- Performance requirements can become quite central to the success of e-Learning. They specify the speed (the system's response time) at which various tasks have to be accomplished. Performance requirements ensure a trouble free function of the system.

- Security requirements describe user's access privileges to the information under the system's control. Users can be given restricted access to e-Learning, including restricted access to data and/or restricted rights to execute certain operations on data. Some of these requirements are related to user requirements.

- Operational requirements determine the hardware/software environment in which the system will operate. These requirements may have an impact on other aspects of the management process of e-Learning, such as system maintenance an update.

- Political requirements are frequently assumed rather than explicitly stated. These requirements are derived from the institutional environment, and specify institutional, legal, and ethical issues. These requirements are very important because the system may be difficult or impossible to use for political, legal, and ethical reasons.

\section{Phase 4: Architecture Design}

The design of e-Learning is usually hierarchical with the top as the home page which presents general information, login, and registration procedures. Basically, the system has five major components: conceptualization, construction, dialogue, learning assessment, and courseware evaluation. Each component is broken down into smaller components according to the requirements described in previous sections. Figure 11 gives an overview of the e-Learning architecture design model. Only the most important components are shown.

\section{Phase 5: User Interface Design}

This phase is concerned with the design of the user interface. General principles of usability engineering and human-computer interaction, including Web design, apply to e-Learning (Shiratuddin, Hassan \& Landoni, 2003; Williams, 2002). User interface design is a central feature, because e-Learning is intrinsic interactive. Thus, to translate users' requirements into a usable e-Learning system, the construction process must be rooted in principles designed for human-computer interaction and user-centered practices, such as ease-of-use and ease-of-learning, efficiency of use, subjective satisfaction, etc. A prototype may also be developed to validate and test some of the most important components of the design, including some interactions with the users.

\section{Phase 6: Implementation}

This phase enables the production of e-Learning elements, e.g. text, graphic, animation, audio, simulation, forms, links to educational software, etc. This is followed by the production of the study material associated with the e-Learning content and associated task-based activities. 


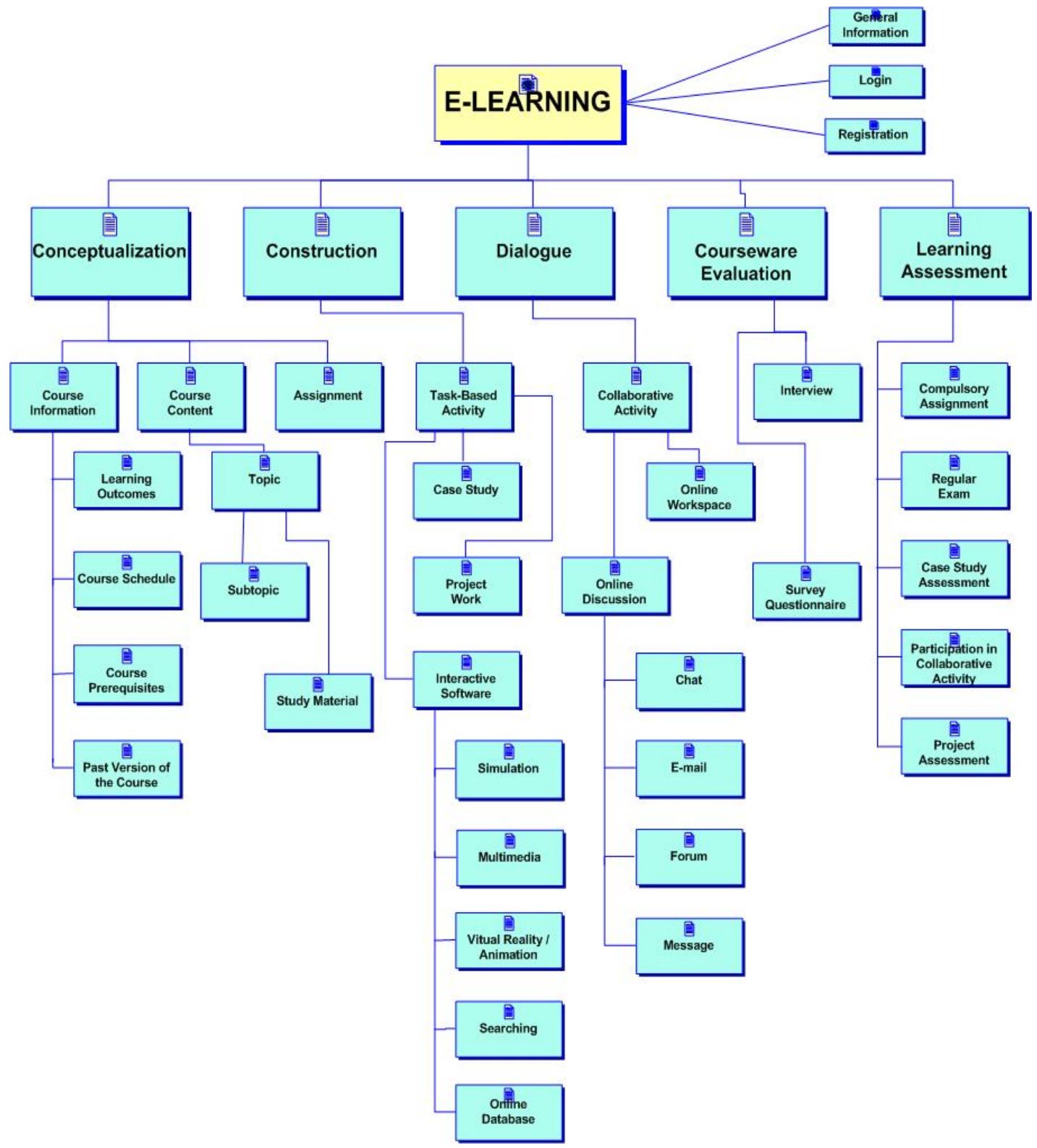

Figure 11: E-Learning architecture design model

Basically, there are two ways of implementing the proposed e-Learning design model:

a) The model can be implemented from the ground using programming languages, such as Java, specialized authoring systems, and tools such as FrontPage or Macromedia Dreamweaver for Web pages, or similar software tools.

b) The model can be implemented using standard software such as LMSs (Learning Management Systems) as these are the most common modes for delivery, or LCMSs (Learning Content Management Systems) as described by (Cohen \& Nycz, 2006). In these cases, it would not be necessary to implement the model from the ground since it is possible to use a campus-wide LMS or LCMS as a platform for e-Learning.

In addition, independently of the chosen solution, pre-existing components and learning objects may be modified, refined, and reused to fit the requirements of the e-Learning system (Cohen \& 
Nycz, 2006). Components may include reusable course units, lessons, exercises, assignments, learning activities, project reports, case studies, past exams, evaluation questionnaires, students' discussions, links to interactive software, and other files, documents, multimedia elements, etc.

Before delivery, e-Learning must be tested systematically. Testing is the process of exercising the system with the intent of finding and ultimately correcting various errors, such as typographical errors, grammatical mistakes, errors in content, errors in graphical and multimedia representations, cross referencing errors, navigation errors, etc. The testing approach to e-Learning adopts the basic principles for software testing, e.g. unit, component and system testing, and software quality criteria.

\section{Phase 7: Delivery and Use}

On the basis of the results of the implementation phase some components of the e-Learning system may be modified and refined before delivery for use in the classroom.

\section{Phase 8: Pedagogical Evaluation}

Once the e-Learning system has been used in authentic educational environments, it must be evaluated to improve its quality (Buzzetto-More \& Pinhey, 2006). The evaluation is to be conducted not only for the purpose of reviewing and revising the technical and design quality, and the quality of the learning material, but also for the purpose of students' learning and the underlying pedagogy, because these are the driving forces behind the development life cycle of eLearning. Clearly, the evaluation of pedagogical issues is critical for e-Learning (Cochrane, 2005; Krauss \& Ally, 2005; Nulden, 2001). The pedagogical evaluation ensures that the objectives are kept in mind, and that the pedagogical decisions made throughout the phases of analysis, design, implementation, and testing are achieved.

There are a number of methods and instruments that may be used to assess the pedagogical value of e-Learning, for example online standard questionnaires, individual and group interviews, and video-taped observation sessions, are relevant instruments to obtain data on what learners feel and think about e-Learning (Cochrane, 2005; Dyson \& Campello, 2003; Storey, Phillips, Maczewski $\&$ Wang, 2002; Williams, 2002). In addition, literature reviews, teacher reflections and expert opinions in educational research are good instruments to elicit the pedagogical value of eLearning.

\section{Phase 9: Evolution}

Considering that e-Learning will undergo change once it is used in the classroom and evaluated, it is necessary to plan an evolution phase in order to ensure that the content is updated and the pedagogy is improved, etc. A continuous evolution is of crucial importance for the quality of eLearning.

\section{A Case Study Using the E-Learning Development Approach}

To illustrate the application of the e-Learning development approach a case study is briefly described, showing the steps teachers and learners would go through in using it. The application of the approach has been described in greater detail in another paper (Hadjerrouit, 2007). This paper summarizes the main ideas. 
The implementation of the approach used a campus-wide Web-based LMS as a platform for eLearning during the academic year of 2005-2006 to teach a course in ICT didactics. The starting point for applying the e-Learning approach to the LMS was to split the learning process into three phases of learning according to the learning cycle: a conceptualization phase, a construction phase, and a dialogue phase:

First, the LMS was designed to support the conceptualization phase, that is to say the process of interaction between the learners' pre-existing knowledge and the key concepts of the subject matter. As a result, the LMS was used as a source for subject information, enabling the access to resources that offer various types of information that can be used to either a greater understanding of the subject matter, or to obtain further information about it. The most important criteria for designing the LMS for conceptualization were a well-structured presentation, easy accessibility, and powerful explanation of the information in order to effectively transmit knowledge to the learners.

Second, the LMS was designed to support the construction phase - the process of building new conceptualizations through the performance of task-based activities. In order to perform their tasks, students should have access to resources that support active, independent, and selfreflective learning. These resources require the design of effective tasks - rather than the presentation of the subject matter - in order to encourage learners to think conceptually. As a result, the resources for the construction phase were designed to contain study material for task-based learning, e.g. well-designed examples of project reports that may be reused with slight modifications, research-based project tasks, links to a wide range of educational software, pedagogical resources that may be adapted, modified, and extended to meet the requirements of students' current work.

Third, the LMS was designed to support the dialogue phase of the learning cycle, enabling students to test their project work through conversations, collaboration, and reflection with the teacher and follow students, to perform synchronous and asynchronous discussions of articles taken from international journals, to share workspaces containing resources to all students, to reuse dialog depositories from past versions of the course, to evaluate the courseware, etc.

The proposed approach to e-Learning was evaluated for the first time in 2005/2006 through survey questionnaires, formal and informal discussions with the students, and teacher's observations. The overall impression of this first, preliminary evaluation was that the majority of the students were globally satisfied with the LMS as a platform for e-Learning. Most students reported that the LMS platform for e-Learning provided support for the conceptualization and construction phases of the learning cycle, through the presentation of the subject matter, adaptation and reuse of learning resources and project reports, task-based activities, and links to pedagogical software applications, etc. The dialogue phase was also supported through students' online submission of compulsory work and teacher feedback, shared workspaces containing resources to all students, online arena for collaborative writing to produce shared documents, online presentation of students' work, and online evaluation. Yet, many interactions and collaborations still happened face-to-face and by means of email, and not through group discussion forum.

At this point, it is impossible to draw any general conclusions from this preliminary evaluation, because it is the first time such an approach to e-Learning was being attempted. New experiments with the e-Learning design model are necessary to gain theoretical and practical insights, and, generate some evidence-based claims about e-Learning development.

\section{Potentialities and Limitations of the Approach}

Developing e-Learning is not a simple process. It is a complex matter and the development process is not an isolated activity. E-Learning is a part of a larger environment that includes educa- 
tional, organizational, pedagogical, and technological dimensions. Particularly important for eLearning is a pedagogical foundation based on learning theories, on the one hand, and the evolutionary character of the construction process, on the other hand. Hence, effective e-Learning must fulfill both system development and pedagogical requirements.

\section{System Development Issues}

To deal with the complexity of constructing e-Learning, there is a need for a systematic system development approach, because, from a software engineering point of view, it could be difficult to succeed without a strict development process and rigorous analysis and design modeling. Thus, selecting a development process model could be a crucial decision to be made by the stakeholders.

The system development approach presented in this paper provides insight into the complexity and specificity of e-Learning development:

1. Independently of the implementation solution (using standard software such as LMSs or developing e-Learning from the ground), constructing e-Learning is a product of a creative act of development, and not a result of repetitive act of manufacturing. Thus, a rigorous development process is a crucial concern for e-Learning in order to avoid faulty solutions, poor design quality, and maintainability.

2. E-Learning development needs to meet the requirements of their stakeholders, that is to say any person affected by the system or who has influence on e-Learning development. This would mean that the stakeholders should be involved throughout the development of e-Learning to ensure that all requirements are met. This, because the main causes of software failure can be traced to the stakeholder factor. The approach specifies the type of user involvement and their participation in the development process. Involving users, in particular teachers, educationalists, and learners, during the development process has many advantages. The drawbacks of e-Learning can be detected and corrected before it is delivered. In addition, involving the users from the very beginning ensures that all relevant perspectives are taken into consideration.

3. The approach is iterative, incremental, and evolutionary as it must deal with change and evolution of many dimensions of e-Learning, in particular course content, which must be constantly evaluated against what is in fact delivered online. Evolution of content is fundamental, since it is an important differentiating factor that separates effective from ineffective e-Learning. In addition, the approach includes an evaluation phase in order to assess the quality of the study material, the students' learning and the underlying pedagogy. The evaluation ensures that the system changes, improves, and evolves according to pedagogical considerations.

4. The approach covers the whole e-Learning development life cycle from analysis, design, implementation, testing, evaluation, and evolution. Pre-existing evolutionary process models have been modified to integrate the educational context and associated teaching and learning environment at an early stage into the system scope. The approach also explicitly incorporates learning theories, since the pedagogical dimension is one of the major forces behind designing, developing, and evaluating e-Learning.

5. The construction process relies on a modeling language, because developers need to build visual models and discuss them with stakeholders and fellow developers. The approach uses the object-oriented modeling language UML for requirements specification and system design. It is an advantage to use UML, because it differs from other modeling languages such as Data Flow Diagrams. It enables to use a common set of terms and con- 
cepts throughout the whole modeling process. In addition, object-orientation is the very basis of learning objects.

6. The construction process focuses on generic features that are common to teaching and learning processes, independent of specific courses, curriculum, and syllabus. Particularly important are general pedagogical principles based on learning theory. Being independent on a particular course extends the applicability, suitability, and flexibility of the approach.

7. Finally, it is clear that many developers of e-Learning are not familiar with formal development methods with UML, since they are not educated as software engineers. Perhaps, they would not completely agree with the statement that a rigorous analysis and design modeling is a prerequisite for developing e-Learning. Nevertheless, it is believed that a systematic and disciplined approach to e-Learning may be necessary to deal with the complexity of constructing e-Learning that supports effective learning.

\section{Pedagogical Issues}

From a pedagogical point of view, the learning cycle and associated primary, secondary, and tertiary courseware hold important lessons for how to design e-Learning according to pedagogical principles built on learning theory.

Pedagogical requirements have been derived from three theoretical perspectives: behaviorist, constructivist and collaborative learning, and the combination of these to the learning cycle with three stages corresponding to the learning theories. The major advantage of adopting such an approach is that it transposes learning theories to an e-Learning design model well understood by teachers and instructors. Given this background, the following conclusions can be drawn:

1. First, the learning cycle provides an adequate pedagogical model for designing eLearning through a cyclical dynamic process starting from conceptualization, progressing through construction to dialogue. More specifically, the learning cycle provides an adequate support for the conceptualization phase - that is the interaction between the learners' prerequisite knowledge and the subject matter. In addition, the learning cycle provides sufficient support for the construction phase of the learning cycle - that is the process of performing task-based activities. Finally, the dialogue phase of the learning cycle is also integrated into e-Learning.

2. Second, even though it would be possible to improve the overall design of e-Learning through a strict development process and rigorous analysis and pedagogical design, it is believed that e-Learning alone is not sufficient for implementing the dialogue phase of the learning cycle. In authentic educational settings, teachers do not just convey subject information and task-based activities that may be available online, but must act as facilitators, guides, and mentors, where dialogue plays a central role. Dialogue can be supported by tertiary courseware through online discussions, both synchronous and asynchronous, but it is a human relation as well. However, online dialogue lacks the very basis of any human dialogue: face-to-face meetings, eye-contact, body language, and nonverbal behavior between teachers and learners. Hence, tertiary courseware alone cannot fully replace the dialogue between teachers and learners. But, it remains to be seen to which extent e-Learning can provide a partial substitute for human dialogue. 


\section{Conclusions and Future Research Work}

Summarizing, this work provides a framework for understanding the issues, challenges, requirements, and basic dimensions of developing e-Learning. In addition, the paper attempts to provide a pedagogical foundation as prerequisite for effective implementation of e-Learning. Such an approach would ensure that e-Learning can be systematically integrated into the educational context.

Improving the approach is an iterative and evolutionary process that progresses through a series of theoretical reflections, experimentations and evaluations. Hence, significant improvements of the approach require time and effort. This work is a long-term research work on the translation and integration of learning theories and pedagogical strategies into e-Learning. The approach will be further developed through continuous cycles of theoretical considerations, implementations, and evaluations in various educational contexts (The Design-Based Research Collective, 2003). Through the iterative and continuous cycle of design, implementation, and evaluation, the author hopes to explore the translation process of learning theories and pedagogical strategies in more details and depth in order to gain theoretical and practical insights in e-Learning development.

The approach will, in future case studies, be used to improve the pedagogical design of the campus-wide LMS. The design will be exposed to a continuous evaluation in order to ensure the relevance, correctness, and completeness of the information available online and the underlying pedagogy rooted in learning theories and associated learning cycle. In line with this research direction, it is important to further investigate the potential of the object-oriented paradigm to eLearning. Object-orientation is indeed a potentially powerful paradigm for developing e-Learning because of its natural parallel with the construction of learning objects.

\section{References}

Ahlemann, F., Haas, C., \& Hoppe, U. (2003). Integrating e-Learning into modern organizations: A reference model. Proceedings of E-LEARN 2003, Phoenix, Arizona (USA), Nov. 7-11, 1147-1154.

Anohina, A. (2005). Analysis of the terminology used in the field of virtual learning. Educational Technology \& Society, 8(3), 91-102.

Balasubramaniam, R., Pries-Heje, J., \& Baskerville, R. (2003). Internet software engineering: A different class of processes. Annals of Software Engineering 14, 169-195.

Bloom, B. S. (1956). Taxonomy of educational objectives: The classification of educational goals. New York: Longman.

Bonk, C. J., \& Graham, C. R. (2006). The handbook of blended learning: Global perspectives, local designs. San Francisco, CA: Pfeiffer Publishing.

Buzzetto-More, N. A., \& Pinhey, K. (2006). Guidelines and standards for the development of fully online learning objects. Interdisciplinary Journal of Knowledge and Learning Objects, 2, 94-104. Available at http://ijklo.org/Volume2/v2p095-104Buzzetto.pdf

Cohen, E. B., \& Nycz, M. (2006). Learning objects and e-learning: An informing science perspective. Interdisciplinary Journal of Knowledge and Learning Objects, 2, 23-34. Available at http://ijklo.org/Volume2/v2p023-034Cohen32.pdf

Cohrane, T. (2005). Interactive QuickTime: Developing and evaluating multimedia learning objects to enhance both face-to-face and distance e-learning environments. Interdisciplinary Journal of Knowledge and Learning Objects, 1, 33-54. Available at http://ijklo.org/Volume1/v1p033-054Cochrane.pdf

Conallen, J. (1999). Modeling web application with UML. New York: Addison-Wesley.

Conole, G., Dyke, M., Oliver, M., \& Seale, J. (2004). Mapping pedagogy and tools for effective learning design. Computers and Education, 43(1-2), 17-33. 
The Design-Based Research Collective. (2003). Design-based research: An emerging paradigm for educational inquiry. Educational Researcher, 32(1), 5-8.

Duffy, T.M., Lowyck, J., \& Jonassen, D.H. (1993). Designing environments for constructive learning. Springer: Berlin.

Dyson, M. C., \& Campello, S. B. (2003). Evaluating virtual learning environments: What are we measuring? Electronic Journal of E-Learning, 1(1), 11-20. Available at http://www.ejel.org/volume-1-issue1/issue1-art2-dyson-campello.pdf

Frantiska, J. J. (2003). Going with the flow: Applying the waterfall model of system development to educational web site creation. Proceedings of E-LEARN 2003, Phoenix, Arizona (USA), Nov. 7-11, 958-965.

Goodyear, P. (2001). Effective networked learning in higher education: Notes and guidelines. Retrieved March 23, 2006, from: http://www.csalt.lancs.ac.uk/jisc/guidelines final.doc

Govindasamy, T. (2002). Successful implementation of e-learning: pedagogical considerations. The Internet and Higher Education, 4, 287-299.

Graf, F. (2002). Providing security for e-Learning. Computers Graphics, 26, 355-365.

Hadjerrouit, S. (2007). Using an understanding of the learning cycle to build effective e-Learning. In N.A. Buzzetto-More (Ed.), Advanced principles of effective e-Learning (pp. 27-58). Santa Rosa, California: Informing Science Press.

Hamid, A. A. (2002). E-Learning: Is it the "e" or the learning that matters? The Internet and Higher Education, 4, 311-316.

Harasim, L. (2000). Shift happens: Online learning as a new paradigm in learning. The Internet and Higher Education 3, 41-61.

Horton, S. (2000). Web teaching guide: A practical approach to creating course web sites. New Haven: Yale University Press.

Karagiorgi, Y., \& Symeou, L. (2005). Translating constructivism into instructional design: Potential and limitations. Educational Technology \& Society, 8(1), 17-27. Available at http://www.ifets.info/journals/8 1/5.pdf

Kay, R., \& Knaack, L. (2005). Developing learning objects for secondary school students: A multicomponent model. Interdisciplinary Journal of Knowledge and Learning Objects, 1, 229-254. Available at http://ijklo.org/Volume1/v1p229-254Kay_Knaack.pdf

Koohang, A., \& Harman, K. (2005). Open Source: A metaphor for e-Learning. Informing Science Journal, 8, 75-86. Available at http://inform.nu/Articles/Vol8/v8p075-086Kooh.pdf

Krauss, F., \& Ally, M. (2005). A study of the design and evaluation of a learning object and implications for content development. Interdisciplinary Journal of Knowledge and Learning Objects, 1, 1-22. Available at http://ijklo.org/Volume1/v1p001-022Krauss.pdf

Laurillard, D. (2002). Rethinking university teaching. A conversational framework for the effective use of learning technologies. London: Routledge

Lin, B., \& Hsieh, C. (2001). Web-based teaching and learner control: A research review. Computers \& Education, 37(3-4), 377-386.

Lowyck, J., \& Poeysae, J. (2001). Design of collaborative learning environments. Computer in Human Behavior, 17(5-6), 507-516.

Maciaszek, L. A. (2001). Requirements analysis and system design: Developing information systems with $U M L$. New York: Addison-Wesley.

Mayes, J. T., \& Fowler, C. J. (1999). Learning technology and usability: A framework for understanding courseware. Interacting with Computers, 11(5), 485-497. 
Mayes, J. T., \& Fowler, C. J. (2005). Mapping theory to practice and practice to tool functionality based on the practitioners' perspective. Retrieved March 28, 2006, from: http://www.jisc.ac.uk/uploaded documents/Stage\%202\%20Mapping\%20(Version\%201).pdf

McCormack, C., \& Jones, D. (1998). Building a web-based education system. New Jersey: Wiley.

MacDonald, C. J., Stodel, E., Thompson, T., Muirhead, B., Hinton, C., Carson, B. et al. (2005). Addressing the learning contradiction: A collaborative approach for developing a conceptual framework learning object. Interdisciplinary Journal of Knowledge and Learning Objects, 1, 79-98. Available at http://ijklo.org/Volume1/v1p079-098McDonald.pdf

Montilva, J. A., Sandia, B., \& Barrios, J. (2002). Developing instructional web sites - A software engineering approach. Education and Information Technologies, 7(3), 201-224. Available at http://www.springerlink.com/content/qh6838g3234561nl/fulltext.pdf

Murugesan, S., \& Ginige, A. (2001). The Essence of web engineering-Managing the diversity and complexity of web application development. IEEE Multimedia, April-June 2001, 8(2), 22-25.

Nash, S. S. (2005).Practices for online courses. Interdisciplinary Journal of Knowledge and Learning Objects, 1, 217-228. Available at http://ijklo.org/Volume1/v1p217-228Nash.pdf

Nocols, M. (2003). A theory of e-learning. Educational Technology \& Society, 6(2), 1-10. Available at http://www.ifets.info/journals/6_2/1.html

Nulden, U. (2001). E-education: Research and practice. Journal of Computer Assisted Learning 17, 363375.

Pahl, C. (2003). Managing evolution and change in web-based teaching and learning environments. Computers \& Education, 40(2), 99-114.

Piaget, J. (1971). Genetic epistemology. W.W. Norton. New York.

Powell, T. A. (1998). Web site engineering: Beyond web page design. Prentice Hall: London.

Pressman, P. (2000). Software engineering: A practitioner's approach (5 $5^{\text {th }}$ ed.). New York: McGraw-Hill.

Roberts, G. (2003). Teaching using the web: Conceptions and approaches from a phenomenographic perspective. Instructional Science, 31, 127-150.

Salas, K., \& Ellis, L. (2006). The development and implementation of learning objects in a higher education setting. Interdisciplinary Journal of Knowledge and Learning Objects, 2, 1-22. Available at http://ijklo.org/Volume2/v2p001-022deSalas.pdf

Salmon, C. (2002). E-Tivities: The key to active online learning. London: Kogan Page.

Shiratuddin, N., Hassan, S., \& Landoni, M. (2003). A usability study for promoting e-content in higher education. Educational Technology \& Society, 6 (4), 112-124. Available at http://www.ifets.info/journals/6 4/11.pdf

Steffe, L. P., \& Gale J. (Eds.). (1995). Constructivism in education. New Jersey: Lawrence Erlbaum Associates.

Stevens, P., \& Pooley, R. (2000). Using UML: Software development with objects and components. London: Addison-Wesley.

Storey, M.A., Phillips, B., Maczewski, M., \& Wang, M. (2002). Evaluating the usability of web-based learning tools. Educational Technology \& Society, 5(3), 91-100. Available at http://www.ifets.info/journals/5_3/storey.pdf

Strodher, J. B. (2003). Cross-cultural issues for Asian e-learners: An analysis based on Hofstede's cultural dimensions. Proceedings of E-LEARN 2003, Phoenix, Arizona (USA), Nov. 7-11, 1978-1983.

Varlamis, I., \& Apostolakis, I. (2006). Present and future of standards for e-Learning technologies. Interdisciplinary Journal of Knowledge and Learning Objects, 2, 59-76. Available at http://ijklo.org/Volume2/v2p059-076Varlamis.pdf 
Vygotsky, L.S. (1978). Mind in society: The development of higher psychological processes. Cambridge. MA: Harvard University Press.

Watson, D. M. (2001). Pedagogy before technology. Re-thinking the relationship between ICT and teaching. Education and Information Technologies, 6(4), 251-266. Available at http://www.springerlink.com/content/w343nq3375053k23/fulltext.pdf

Wiley, D.A. (2000). Connecting learning objects to instructional design theory. A definition, a metaphor, and a taxonomy. Retrieved January 22, 2006, from: http://reusability.org/read/chapters/wiley.doc

Williams, D. D. (2002). Improving use of learning technologies in higher education through participant oriented evaluations. Educational Technology \& Society, 5(3), 11-17. Available at http://www.ifets.info/journals/5_3/williams.pdf

Youm, J. H., \& Black, J. B. (2005). The potential for an object-oriented model of learning. Proceedings of E-LEARN 2005, Nov 1-5, Washington DC, USA, 1583-1586.

\section{Biography}

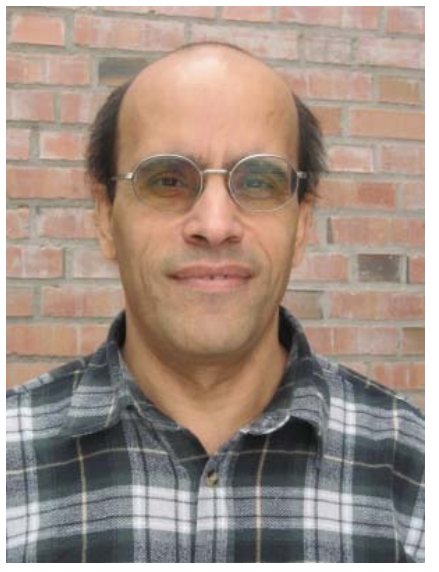

Said Hadjerrouit received the MS and $\mathrm{PhD}$ degrees in Software Engineering and Artificial Intelligence from the Technical University of Berlin (Germany), in 1985 and 1992, respectively. He joined Agder University College, Kristiansand (Norway) in 1991. He is currently an Associate Professor of Computer Science at the Faculty of Mathematics and Sciences. He has been in the teaching profession for 25 years. He has extensive experience teaching object-oriented programming, Web design, database development, software engineering, and didactics of informatics. His research interests include object-oriented software development with the UML, computer science and software engineering education, didactics of informatics, use of ICT in mathematics education, development of e-Learning and Web-based learning systems. Hadjerrouit has published over 45 papers in international journals and conference proceedings. 